\title{
Anti Cutaneous Aging Effect of Red Djulis (Chenopodium formosanum) Extract on Gene Expression of Human Dermal Fibroblast
}

\author{
Yung-Hsiang Lin ${ }^{1}$, Yung-Kai Lin ${ }^{2,3 *}$, Shu-Ting Chan ${ }^{1 * *}$, Yu-Ming Chun ${ }^{1 * *}$, Yu-Ting Lin ${ }^{1 * *}$, Kai- \\ Wen Kan ${ }^{1}$ and Chin-Hsiu Y $\mathbf{u}^{1}$ \\ ${ }^{1}$ Research \& Design Center, TCI Co., Ltd., Taipei, Taiwan \\ ${ }^{2}$ Institute of Food Safety and Risk Management, National Taiwan Ocean University, Keelung City 202, \\ Taiwan \\ ${ }^{3}$ Graduate Institute of Biomedical Engineering, National Chung Hsing University, Taichung 402, Taiwan \\ * Corresponding author: YKLin@nchu.edu.tw \\ **Eual contribution
}

\begin{abstract}
Red djulis (Chenopodium formosanum) is a native cereal plant in Taiwan; it contains abundant polyphenols, betalian and dietary fiber. The appearance of red djulis is bright red. Therefore, it is also called the "ruby of cereals". The antioxidative activity of red djulis extract is well-understood. However, the antiaging function still remains unclear. This study examined the potential of red djulis extract for enhancing collagen secretion and preventing cutaneous aging using red djulis extracts. The red djulis extracts are comprised of an abundant active component that can effectively enhance the ability of collagen secretion of dermal fibroblasts, prevent the glycation of collagen and resist the damage of ultraviolet light exposure. After fibroblast treatment with red djulis extracts, TGM1, KRT1, KRT10 and SOD2 genes were up-regulated significantly by 2.3, 4.3, 4.4 and 27.3 times, respectively, compared to those of the control group. Additionally, it can increase COL1A2 gene expression by $43 \%$ and decrease $M M P 9$ gene expression 33\%. Therefore, it was demonstrated that red djulis extracts affect gene expressions related to the skin barrier, antioxidation and collagen. Moreover, we found positive effects on skin barrier integrity, endogenous antioxidant activity and skin collagenpreservation. The preparation of the red djulis extracts is environmental friendly and can promote the economic value of Chenopodium formosanum; thus, the proposed extract is suitable for applications in the development of food products, especially beverages, skin care and cosmetic products.
\end{abstract}

Keywords: Chenopodium formosanum; Human Dermal Fibroblast; UV Exposure; Antioxidant Activity; Anti-Aging; Red Djulis

\section{Introduction}

Collagen, one of the primary extracellular matrix (ECM) components of the dermis, is the most abundant protein in mammals, comprising about $30 \%$ of total protein[1-4]. Collagens co-polymerize to form extended mechanically stiff fibrils which confer tensile strength to the tissue providing the elasticity of skin[5]. However, the overall collagen content per unit area of the skin surface is known to diminish approximately $1 \%$ per year leading to gradual loss of skin elasticity (sagging) with age (intrinsic aging)[6, 7]. Additionally, chronic sun exposure leads to marked degradation of skin collagen structure resulting in wrinkle formation in photo aged skin (extrinsic aging)[8]. Therefore, in addition to sun exposure prevention, novel and effective anti-aging ingredients for skin care have drawn a lot of attention[9, 10].

Red djulis is a native cereal plant in Taiwan. The whole plant is colorful and traditionally called the "ruby of cereals" for its bright red grain color (Figure 1). Besides the high content of dietary fiber and starch, red djulis also possesses high protein levels and abundant essential amino acids, which make it a nutritious food. Djulis is particularly rich in lysine, which increases calcium absorption to help build collagen, and acts as a building block for the fibrils and fibers of collagen[5, 8, 11]. What is 
more, the batalain pigment in djulis is considered to possess not only good coloring potential but also positive physiological benefits for human health, such as melanoma cell growth inhibition and boosting of antioxidant activity[11-14], through antioxidant molecules such as betacyanin, mesembryanthin, and other polyphenols and flavonoids[11, 12]. Chyau et al., revealed the role of the ethanolic extracts of red djulis (Chenopodium formosanum) and its bioactive compounds in preventing adipogenesis in 3T3-L1 adipocytes[15]. Specifically, treatment with red djulis extracts under UVB light exposure can induce an accumulation of betacyanins and flavonoids in the immortal keratinocyte cell line (HaCat) for protection against UV-induced damage[14]. In addition, red djulis extracts have been reported to have antioxidant and moisturizing effects, and can stimulate the proliferation of fibroblasts and keratinocytes in the course of wound healing and regeneration[14, 16]. Therefore, djulis extracts contain an abundance of antioxidants and may act as an active ingredient for skin care product $[17,18]$. Therefore, this in vitro study using genetic analysis aims to determine the anti- Cutaneous aging effect of red djulis extract and exploring the feasibility of application in the biomedical field.

\section{Materials and Methods}

\subsection{Preparation and antioxidant analysis of red djulis extract}

The red djulis used in the present study (Chenopodium formosanum) was purchased from Pingtung County, Taiwan. The whole grain red djulis (unhulled) stored at $4{ }^{\circ} \mathrm{C}$ prior to use. To achieve optimal extraction conditions, before carrying out the extraction step of the present study, $2.5 \mathrm{~g}$ of grounded red djulis was combined was $25 \mathrm{~mL}$ of water to form a mixture, and extracted with water at different temperatures for 30 minutes. The ratio of grounded red djulis to water was 1:10 (w / v), and the temperatures used for extraction were $25^{\circ} \mathrm{C}, 50^{\circ} \mathrm{C}$, and $70{ }^{\circ} \mathrm{C}$, respectively. The mixture was then centrifuged at $4600 \mathrm{X} \mathrm{g}$ for 20 minutes to separate solid substances. The supernatant was collected after centrifugation and final filtration before subjecting the red djulis extract to analysis. Further, sonication at $40 \mathrm{kHz}$ was applied to facilitate red djulis extraction. Finally, the red djulis extract was disinfected and sterilized at $121^{\circ} \mathrm{C}$ for 15 minutes, stored in a sealed container at $4{ }^{\circ} \mathrm{C}$ and kept out of light.

The antioxidant analysis of red djulis extract was applied using total phenol content by the FolinCiocalteu colorimetric method. Four $\mathrm{mL}$ of $2 \%$ sodium carbonate water solution and $5 \mathrm{~mL}$ of FolinCiocalteu reagent was added to red tubes with $1 \mathrm{~mL}$ djulis extract or standard solution. The standard solution was gallic acid at a concentration of 200 to $1000 \mathrm{mg} / \mathrm{mL}$. (7.5\% in water) in order to create basic conditions $(\mathrm{pH} \sim 10)$ for the redox reaction between phenolic compounds and the FolinCiocalteu reagent. After incubation for $90 \mathrm{~min}$ at room temperature, the absorbance was read at 750 $\mathrm{nm}$ by a microplate reader (BioTek Instruments, Winooski, VT), against the blank. After incubation at $25^{\circ} \mathrm{C}$ for 30 minutes, absorbance was measured as $750 \mathrm{~nm}$ by the microplate reader (BioTek Instruments, Winooski, VT), against the blank. Total phenolic content was expressed as the equivalent of gallic acid.

The total flavonoid content of crude extract was determined by the aluminium chloride colorimetric method[19]. Fifty $\mu \mathrm{L}$ of red djulis extract was increased to $1 \mathrm{~mL}$ with methanol, mixed with $4 \mathrm{~mL}$ of distilled water and then $0.3 \mathrm{~mL}$ of $5 \% \mathrm{NaNO}_{2}$ solution; $0.3 \mathrm{~mL}$ of $10 \% \mathrm{AlCl}_{3}$ solution was added after $5 \mathrm{~min}$ of incubation, and the mixture was reacted for $6 \mathrm{~min}$. Two $\mathrm{mL}$ of $1 \mathrm{~mol} / \mathrm{L}$ $\mathrm{NaOH}$ solution were added, and the final volume of the mixture was brought to $10 \mathrm{~mL}$ with doubledistilled water. The mixture was reacted for $15 \mathrm{~min}$; absorbance was measured at $500 \mathrm{~nm}$. The total flavonoid content was calculated from a calibration curve, and the result was expressed as mg rutin equivalent per g dry weight.

\subsection{Chemical characterization}

Varian 400 NMR instrument was used to record ${ }^{1} \mathrm{H}$ NMR and ${ }^{13} \mathrm{C}$ NMR spectrums. The chemical shifts of spectroscopic data are given in $\delta$ (ppm) and coupling constants in hertz $(\mathrm{Hz})$. Bruker amaZon SL mass spectrometer equipped with an ESI ionization source (Bruker, Bremen, Germany) was used 
for acquiring mass data. The HPLC system was composed of Hitachi L-2310 series pump (Hitachi, Tokyo, Japan), L-2420 UV-VIS detector (Hitachi, Tokyo, Japan), and an ODS column (5 $\mu \mathrm{m}, 250 \times 10$ mm, Discovery ${ }^{\circledR} \mathrm{HS}_{18}$, Supelco Inc., Tokyo, Japan). The Medium pressure liquid chromatography (MPLC) was performed on a CombiFlash ${ }^{\circledR} \mathrm{Rf}^{+}$(Teledyne ISCO, Lincoln, USA). Sephadex LH-20 (Amersham Pharmacia Biotech AB, Sweden) was used for separation. LiChrospher ${ }^{\circledR}$ Si 60 (5 $\mu \mathrm{m}, 250$ 10, Merck, Darmstadt, Germany) and LiChrospher ${ }^{\circledR} 100$ RP-18e (5 $\mu \mathrm{m}, 250-10$, Merck, Darmstadt, Germany) were used for NP-HPLC and RP-HPLC (Merck, Darmstadt, Germany), respectively.

\subsection{Cell lines and chemicals}

The human skin fibroblast cell line CCD-966SK (CRL-1881) was derived from the American Type Culture Collection (Manassas, VA, USA). All cell culture media and reagents including MTT [3-(4,5dimethylthiazol-2-yl)-2,5-diphenyltetrazolium bromide] were purchased from Sigma-Aldrich (St. Louis, MO, USA) or Gibco (Thermo Fisher Scientific, Inc., Carlsbad, CA, USA) and were of reagent grade or cell-culture grade. Cells were cultured in MEM with 10\% fetal bovine serum, and incubated at $37^{\circ} \mathrm{C}$ in a humidified atmosphere of $5 \% \mathrm{CO} 2$.

\subsection{Cell viability}

Briefly, cells were seeded into 96-well plates at a density of $5 \times 10^{3}$ cells/well. After $24 \mathrm{~h}$ of culturing, the medium was removed and replaced with a fresh medium containing various concentrations $(0.25,0.5,1$ and $2 \mathrm{mg} / \mathrm{mL})$ of red djulis extract. Cell viability was assessed through MTT assay. Briefly, $15 \mu \mathrm{l}$ of 3-(4,5-Dimethylthiazol-2-yl)-2,5-diphenyltetrazolium bromide (MTT) (Sigma; $4 \mathrm{mg} / \mathrm{ml}$ ) was added and the cells were incubated for an additional 4 hours. The medium was removed and $50 \mu \mathrm{l} /$ well of DMSO was added to resolve formazan crystal. The plate was placed on a shaker and incubated for $10 \mathrm{~min}$ and the absorbance was measured at $570 \mathrm{~nm}$. Cell viability in response to treatment was calculated as: Cell viability $(\%)=(\mathrm{OD}$ sample $/ \mathrm{OD}$ control $) \times 100 \%$.

\subsection{Quantification of gene expressions by real-time PCR}

The treated CCD-966SK fibroblasts or human primary epidermal keratinocytes were harvested, and total RNA was isolated from cells using an RNA purification kit (Geneaid, Taiwan). DNA-free total RNA was reversely transcribed to cDNA using a SuperScript ${ }^{\mathrm{TM}}$ Reverse Transcriptase kit (Invitrogen, Life Technologies Co., CA, USA). Quantitative real-time PCR was conducted using an ABI StepOnePlus ${ }^{\mathrm{TM}}$ Real-Time PCR System (Thermo Fisher Scientific, Inc., CA, USA) and the SYBR Green Master Mix (KAPA Biosystems, MA, USA) for was used transcript measurements. The reaction mixture was cycled as follows: One cycle at $95^{\circ} \mathrm{C}$ for $20 \mathrm{~s}$, followed by 40 cycles of $95^{\circ} \mathrm{C}(1 \mathrm{~s}), 60^{\circ} \mathrm{C}$ $(20 \mathrm{~s})$, and plate reading was conducted after each cycle. The melting curves of the PCR products were analyzed during the quantitative real-time PCR. The gene-specific primers used in this study are listed in Table 1. Real-time PCR reactions were performed using the ABI StepOnePlusTM system with KAPA SYBR FAST ABI Prism (KAPA). Antioxidant-related genes (SOD2 and CAT) and collagen-related genes (COL1A1 and TIMP1) were detected (Table.1). GAPDH was used as the reference gene to normalize relative expression. The GAPDH gene was used as a normalization control. Data were analyzed using the ABI StepOne ${ }^{\mathrm{TM}}$ Software v2.2.3 (Thermo Fisher Scientific, Inc., Carlsbad, CA, USA). All PCR assays were performed in duplicate three times.

\subsection{Wound healing assay}

In vitro wound scratch assay was performed as described in Yarrow et al.[20] with modifications. Briefly, CCD-966SK cells were grown to $80 \%$ confluence in 24 -well plates. The scratching was performed by scraping with a sterile 1-ml pipette tip across the center of the well, followed by incubation with media only (mock) or with $2 \mathrm{mg} / \mathrm{ml}$ of SGE in culture media for $17 \mathrm{~h}$. The wound closures were subsequently photographed under a microscope (Eclipse Ti-U, Nikon Corporation, Tokyo, Japan) using a CCD digital camera. Cell migration was analyzed by Image J (image processing and analysis in Java: https://imagej.nih.gov/ij/download.html) and expressed as percentage of wound 
coverage by cells moving into the scratched wound area. Cell migration data were expressed as the percentage of wound coverage.

\subsection{Antiglycosylation analysis}

AGE formation was determined by using collagen and fructose as glycation reactants. The modification procedure was described as in previous study by Peter-Katalinić (2005)[21]. Collagen solution $(60 \mathrm{mg} / \mathrm{mL})$ and fructose $(1.5 \mathrm{M})$ were prepared in $0.2 \mathrm{M}$ potassium phosphate buffer $(\mathrm{pH}$ 7.4 , containing $0.06 \%$ sodium azide). For each reaction of glycation, $250 \mu \mathrm{L}$ of collagen solution, 250 $\mu \mathrm{L}$ of fructose solution, and $250 \mu \mathrm{L}$ of deionized water diluted sample or control $(3 \mathrm{mM}$ aminoguanidine) were mixed. $100 \mu \mathrm{L}$ of the above mixture was withdrawn immediately to a well of a 96-well plate and subjected to intensity determination by a spectrofluorometer (Paradigm microplate reader, Beckman Coulter, Fullerton, CA, USA) set at $360 \mathrm{~nm}$ of excitation and $460 \mathrm{~nm}$ of emission. The data were defined as Fluorescence sample $0 \mathrm{hr}$ or Fluorescence control $0 \mathrm{hr} .450 \mu \mathrm{L}$ of the remaining mixtures were taken into a $1.5 \mathrm{~mL}$ microfuge tube and incubated at $50^{\circ} \mathrm{C}$ for $24 \mathrm{hr}$. After incubation, the reacted solutions were measured with a spectrofluorometer again and the result was defined as Fluorescence sample $24 \mathrm{hr}$ or Fluorescence control $24 \mathrm{hr}$. The antiglycosylation activity rate of the sample was calculated as follows:

Antiglycosylation activity $(\%)=$

\section{Fluorescence sample 24hr- Fluorescence sample}

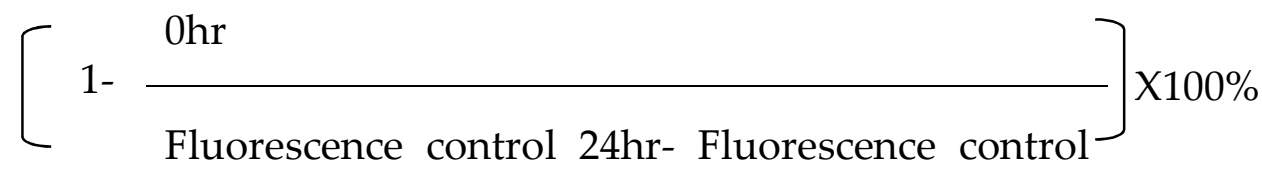

Ohr

\subsection{Collagen secretion assay}

The soluble collagen was determined by the method described by Aramwit et al. (2009). Human skin fibroblast cells (CCD-966SK) were seeded at an initial concentration of $4 \times 10_{4}$ cells per well of 24-well plate in MEM containing 10\% FBS. After $24 \mathrm{~h}$, the culture medium was replaced by fresh medium. The sample extracts were diluted with various concentrations with phosphate buffer saline (PBS) and added into each well. Cells without a sample extract served as negative controls. After incubation for $48 \mathrm{~h}$ at $37^{\circ} \mathrm{C}$ with $5 \% \mathrm{CO} 2$, the supernatants were collected. The total amount of soluble collagen type I was assayed using the Sircol ${ }^{\circledR}$ Collagen Assay Kit (Bicolor Life Science Assays, Northern Ireland, UK). Briefly, $100 \mu \mathrm{L}$ of experimental supernatant was mixed with $1 \mathrm{~mL}$ of dye solution at room temperature for $30 \mathrm{~min}$. Then the samples were centrifuged at 15,000 $\times \mathrm{g}$ for $10 \mathrm{~min}$ to form a pellet of collagen. The supernatant was removed and the soluble collagen produced was dissolved in $1 \mathrm{~mL}$ of alkali reagent. The resultant alkali reagent solutions were assayed by a spectrophotometer at a wavelength of $540 \mathrm{~nm}$. The amount of collagen was calculated based on a standard curve of soluble collagen (bovine skin collagen type I standard from American disease free animals).

\subsection{Collagen immunofluorescence staining}

For immunohistochemistry, antigen retrieval was performed by heating sections of $10 \mathrm{mM}$ citrate buffer ( $\mathrm{pH}$ 6.0) in a microwave oven. Reactions with endogenous peroxidases and proteins were blocked by incubation with $3 \% \mathrm{H}_{2} \mathrm{O}_{2}$ diluted in methanol and $10 \%$ normal goat or rabbit serum, 
depending on the host animal for the secondary antibody. Then incubation with primary antibodies was done overnight at $4{ }^{\circ} \mathrm{C}$. The primary antibodies used were as follows: rabbit anti-collagen I (1:50; Abcam, Cambridge, UK), rabbit anti-collagen III (1:100; Abcam), mouse anti-collagen IV (1:50; Dako, Glostrup, Denmark), rabbit anti-collagen V (1:50; Abcam), and rabbit anti-collagen VI (1:50; Abcam). The EnVision labeled polymer-HRP system (Dako) was used as the secondary antibody and peroxidase activity was visualized with a liquid diaminobenzidine substrate (Dako). Nuclei were counter-stained with hematoxylin. Collagen staining of the nodular lesions was classified into three categories according intensity compared with background staining (strongly positive, weakly positive, and negative).

\subsection{Trosinase activity inhibition assay}

Trosinase activity inhibition assay was conducted following Chan et al (2011)[22]. Briefly, $100 \mu \mathrm{l}$ of freshly prepared L-DOPA solution, at different concentrations $(2.5,5.0$ and $10.0 \mathrm{mM})$, was added for dopachrome formation. The relationship between total protein and concentration of L-DOPA for dopachrome formation was observed. The reaction mixture $(200 \mu \mathrm{l} /$ well $)$ consisting of cell-extracted protein and L-DPA in $0.1 \mathrm{M}$ sodium phosphate buffer ( $\mathrm{pH}$ 6.8) was added into wells of a 96-well plate in triplicate. The plate was incubated at $37^{\circ} \mathrm{C}$ and absorbance was measured at $475 \mathrm{~nm}$ for a time course of up to 4 hours.

\subsection{Statistical analysis}

The significance of treatment was evaluated using paired t-test with the software Statistical Product and Service Solutions (SPSS ${ }^{\circ}$ 18.0; SPSS Inc., Chicago, IL). A difference was considered statistically significant when the $\mathrm{p}$ value was $<0.05$. All results were expressed as mean \pm standard deviation (SD).

\section{Result and Discussion}

\subsection{Optimal extraction condition of red djulis extracts}

When evaluating the optimal conditions for total flavones and total phenol content from red djulis, the amount of total flavones and total phenol may be affected by the type of solvent, $\mathrm{pH}$ level, solvent-water ratio and extraction time[23]. To avoid the Islamic legal limitations and cost consideration, authors decided to use water extraction. The antioxidant compounds of different extraction conditions are shown in Table 2. The amount of total flavones and total phenol of the unhulled red djulis groups were higher than those of hulled red djulis and the difference reached almost three to four fold. Furthermore, the maximum amount of total flavones and total phenol extract from red djulis was obtained from unhulled red djulis at $50^{\circ} \mathrm{C}$ for 30 minutes. A previous study revealed that the djulis hull contains numerous antioxidant compounds and could be used to develop functional foods[16, 24]. Therefore, we decided to obtain extracts from unhulled red djulis at $50^{\circ} \mathrm{C}$ for 30 minutes for further experiments.

\subsection{Chemical characterization}

The obtained extract was partitioned with ethyl acetate (EtOAc), inclusive of n-butanol (n$\mathrm{BuOH}$ ) to obtain EtOAc layer (12.3 g), n-BuOH layer (22.1 g) and $\mathrm{H}_{2} \mathrm{O}$ layer (108.7 g) respectively. Following the bioassay-guided fractionation isolation (BGFI), the EtOAc layer was subjected to a Sephadex LH-20 and eluted with MeOH to yield 9 fractions (Fr. 1-Fr. 9). Later on, Fr. 2 was separated by MPLC with LiChroprep ${ }^{\circledR}$ RP-18 to afford five fractions (Fr. 2-1-Fr. 2-5) by elution with a linear gradient of mixtures of $\mathrm{MeOH}-\mathrm{H} 2 \mathrm{O}$ (from 10:90 to 90:10). Fr. 2-2 was subjected to preparative HPLC with a Discovery ${ }^{\circledR}$ HS C18 $(250 \times 10 \mathrm{~mm}, 5 \mu \mathrm{m})$ column and eluted by mixtures of $\mathrm{MeOH}-\mathrm{H} 2 \mathrm{O}$ (10:90), to yield compound $2(3.2 \mathrm{mg})$. Fr. 3 was purified by preparative HPLC with isocratic solvent system MeOH-H2O (30:70), to afford compound 1 (5.2 mg). Fr. 4 was loaded onto a preparative HPLC system and eluted by mixtures of $\mathrm{MeOH}-\mathrm{H} 2 \mathrm{O}$ (20:80) to yield compound 4 (4.6 mg). Fr. 5 was treated 
similarly to yield compound 6 (10.0 mg). However, Fr.6 was applied to a RP-18 column by MPLC eluted with a gradient solvent of mixtures of $\mathrm{MeOH}-\mathrm{H} 2 \mathrm{O}$ (from 10:90 to 90:10) and further purified by HPLC with mixture of MeOH-H2O (35:65) to obtain compound $3(5.6 \mathrm{mg})$ and compound 5 (20.3 $\mathrm{mg}$ ). The structures of all isolates were determined by analysis of their spectroscopic data (NMR and MS) data shown in Figure 2 and Figure. 3, the promote ability of collagen secretion will be discuss at later sections.

\subsection{In Vitro Efficacy Evaluation}

\subsubsection{Cytotoxicity Assessment}

The effect of red djulis extracts on cell viability of human dermal fibroblasts (CCD-966SK) was analyzed. The results showed that cell viabilities of red djulis extracts with concentrations of 0.1875 to $3 \mathrm{mg} / \mathrm{mL}$ were not significantly different with those of the control group (100\%) (Figure 4$)$. The results indicated that red djulis extracts are without cytotoxic compound.

\subsubsection{Wound Healing Assay}

The wound healing rate of red djulis extracts was 2.3 fold greater than that of the control group. After $24 \mathrm{~h}$ exposure to the test sample, red djulis extracts were enhanced so that the cell migrates towards the provisional gap (Figure. 5). According to comprehensive cytotoxicity results, the red djulis extracts had low cytotoxicity and enhanced cell migration. These results seem to be correlated with of antioxidant compound of red djulis extracts.

Every living cell that undergoes aerobic metabolism produces reactive oxygen species (ROS) as its byproduct. The ROS is removed by antioxidative compounds of red djulis extracts, thus maintaining the healing physiological functions of fibroblast. Our findings are consistent with those of previous studies[14, 25, 26].

\subsubsection{Gene Expressions of CCD-966SK Fibroblasts}

Skin-barrier-related genes (TGM1, KRT1, KRT10), antioxidant-related genes (SOD2) and collagen-related genes (COL1A1 and MMP9) were selected for analysis of the mRNA expression in human dermal fibroblasts (CCD-966SK) by qPCR. The TGM1 gene provides instructions for producing an enzyme called transglutaminase 1 . This enzyme is involved in the formation of the cornified cell envelope, which is a structure that surrounds skin cells and helps to form a protective barrier between the body and the environment. The KRT1 and KRT10 gene encode a member of the type I (acidic) and type II (basic or neutral) cytokeratin families, respectively. They are coexpressed during the differentiation of the epithelial tissues. The SOD2 gene encodes superoxide dismutase 2 (SOD2, mitochondrial), which is a member of the iron/manganese SOD family, catalyzing the dismutation of the superoxide radical into hydrogen peroxide or oxygen. The COL1A2 (collagen type I alpha 2) encodes the pro-alpha2 chains of type I collagen, which is a fibril-forming collagen found in most connective tissues and is abundant in dermis, bone, cornea and tendon. The MMP9 gene encodes matrix metallopeptidase 9, which is a class of enzymes involved in the degradation of the extracellular matrix (collagen) [11]. The "photo aging" or "photo-aging effect" refers to aging cells with UV light caused by factors including but not limited to UV light activated protein kinase pathway split via silk (MAP Kinase pathway) and increased phosphorylation of the dermal layer of matrix metalloproteinase (matrix metalloproteinases, MMPs) content. The matrix metalloproteinases decomposes collagen, decreasing the collagen content of the skin; will promote the UV light reactive oxygen species (reactive oxygen species, ROS), such as oxygen ions, free radicals and peroxides such as organic and inorganic produce, other cause denaturation of collagen (denature) and loss of function.

In the present study, after treatment with red djulis extracts, TGM1, KRT1, KRT10 and SOD2 genes were up-regulated significantly 2.3, 4.3, 4.4 and 27.3 times, respectively, compared to those of the control group (Figure 6). Additionally, the extract can increase COL1A2 gene expression $43 \%$ and decrease MMP9 gene expression 33\% (Figure 7). Therefore, it was demonstrated that red djulis 
extracts affect the gene expressions related to skin barrier, antioxidation and collagen, and shows positive effects on skin barrier integrity, endogenous antioxidant activity and skin collagenpreservation.

\subsection{Stimulation of Collagen Secretion}

After treatment with red djulis extracts, collagen content in human dermal fibroblast obviously increased based on immunofluorescence staining compared with the control (Figure 8 a). Additionally, the collagen content of the red djulis extract group was about 1 higher than that of the control group (Figure $8 \mathrm{~b}$ ). These results revealed that red djulis extracts can promote collagen secretion from skin fibroblast cells.

Analysis of red djulis extract used in this study show that the extract promotes the secretion of collagen, wherein the vertical axis represents the percentage of collagen secretion rates, with the control group shown as $100 \%$ for the sake of reference. According to the findings, with $0.2 \mathrm{mg} / \mathrm{mL}$ of unhulled treated red djulis extract, collagen secretion in human skin fibroblasts reached $138 \%$ compared to the untreated control group. Thus, treatment with red djulis extract led to an increase of $38 \%$; and 0 . shelling red djulis extract treated $2 \mathrm{mg} / \mathrm{mL}$ of collagen secretion rates of human skin fibroblasts $201.4 \%$ is reached, the control group protein secretion in human skin fibroblasts treated to extract collagen without red djulis rate more than 2 times. Furthermore, the fractions of TCI-CF-01 TCI-CF-02 and TCI-CF-03 from red djulis extract treated $20 \mathrm{mg} / \mathrm{mL}$ of collagen secretion rates of human skin fibroblasts $133.3 \% 122.9 \%$ and $119.8 \%$ are reached, respectively (Figure 8c). Thus, experiments confirmed that unhulled red djulis extract, hulled red djulis extract and fractions of red djulis extract can effectively promote the collagen secretion rate of cells.

\subsection{Anti- Advanced Glycation End-products (AGEs)}

Red djulis extracts inhibited the formation and accumulation of Amadori Product (primary glycation products), $\alpha$-dicarbonyl compounds (secondary glycation products) and Advanced Glycation End-products (AGEs), only 18.8\% compared with the control (Figure 9). The results showed that red djulis extracts decreased the formation of AGEs and the glycation of collagen. The experiment indicated that red djulis extracts have the ability to protect and maintain the function of collagen in the skin. Moreover, according to our analysis, red djulis extracts inhibit the glycation of collagen. The extract reached an optimal effect at a concentration of $8 \%(\mathrm{w} / \mathrm{w})$, inhibiting collagen glycation by up to $81.2 \%$ (Figure 9).

\subsection{Red Djulis Extracts Inhibited Melanin Synthesis}

The result showed that after treatment with different doses of red djulis extracts, the tyrosinase activity was significantly inhibited by $30 \%$ and $43 \%$ compared with the control group (Figure 10), and the result was dose dependent. Red djulis extracts also significantly reduced melanin synthesis by about $30 \%$ compared to the control group (Figure 8 ). This study indicated that red djulis extracts had a whitening effect by reducing the activity of tyrosinase, a key enzyme in melanin synthesis, and inhibiting melanin synthesis.

\section{Conclusion}

In summary, red djulis extracts contain abundant bioactive compounds rich in flavonoids and phenolic 1S. Thus, the extract not only promotes secretion of collagen of dermal fibroblasts, but also effectively inhibits the glycation effect, and may enhance the dermal fibroblasts viability and migration rate. After fibroblasts were treated with red djulis extracts, TGM1, KRT1, KRT10 and SOD2 genes were up-regulated significantly by $2.3,4.3,4.4$ and 27.3 times, respectively, compared to those of the control group. Additionally, the extract can increase the COL1A2 gene expression by $43 \%$ and decrease MMP9 gene expression by 33\%. Therefore, it was demonstrated that red djulis extracts affect gene expressions related to the skin barrier, antioxidation and collagen. The results show positive effects on skin barrier integrity, endogenous antioxidant activity and skin collagen-preservation. 
Furthermore, the water soluble red djulis extracts do not harm the environment and could provide flexible formulation for safe anti-aging skin care products, cosmetic raw materials or functional beverages.

\section{Reference}

1. Lin, Y. K.; Liu., D. C., Comparison of physical-chemical properties of type I collagen from different species. Food Chemistry 2006, 99, 244-251.

2. Lin, Y. K.; Liu, D. C., Studies of novel hyaluronic acid-collagen sponge materials composed of two different species of type I collagen. J Biomater Appl 2007, 21 (3), 265-81.

3. Lin, Y. K.; Kuan, C. Y., Development of 4-Hydroxyproline Analysis Kit and Its Application in Collagen Quantification. Food Chemistry 2010, 119 (3), 1271-1277.

4. Lin, Y. K.; Lin, T. Y.; P., S. H., Extraction and characterisation of telopeptide-poor collagen from porcine lung. Food Chemistry 2011, 124 (4), 1583-1588.

5. Yamauchi, M.; Sricholpech, M., Lysine post-translational modifications of collagen. Essays in biochemistry 2012, 52, 113-133.

6. Shuster, S. A. M.; Black, M. M.; McVitie, E. V. A., The influence of age and sex on skin thickness, skin collagen and density. British Journal of Dermatology 1975, 93 (6), 639-643.

7. Naylor, E. C.; Watson, R. E. B.; Sherratt, M. J., Molecular aspects of skin ageing. Maturitas 2011, 69 (3), 249256.

8. Bailey, A. J., Molecular mechanisms of ageing in connective tissues. Mechanisms of Ageing and Development 2001, 122 (7), 735-755.

9. Lin, Y.-H.; Lin, Y.-K.; Lin, Y.-H., Validation of Anti Cutaneous Aging Effect of Red Djulis (Chenopodium formosanum) Extract on Gene Expression of Human Dermal Fibroblast. Journal of Biobased Materials and Bioenergy 2019, 13 (4), 570-575.

10. Lin, Y.-H.; Lin, Y.-K.; Shen, Y.-C., Evaluation Effects of Peanut Skin Extract on Blood Glucose Regulation and Body Fat Reduction. Journal of Biobased Materials and Bioenergy 2017, 11 (3), 242-247.

11. Wu, L.-c.; Hsu, H.-W.; Chen, Y.-C.; Chiu, C.-C.; Lin, Y.-I.; Ho, J.-a. A., Antioxidant and antiproliferative activities of red pitaya. Food Chemistry 2006, 95 (2), 319-327.

12. Tsai, P.-J.; Chen, Y.-S.; Sheu, C.-H.; Chen, C.-Y., Effect of Nanogrinding on the Pigment and Bioactivity of Djulis (Chenopodium formosanum Koidz.). Journal of Agricultural and Food Chemistry 2011, 59 (5), 1814-1820.

13. Hsu, B. Y.; Lin, S. W.; Inbaraj, B. S.; Chen, B. H., Simultaneous determination of phenolic acids and flavonoids in Chenopodium formosanum Koidz. (djulis) by HPLC-DAD-ESI-MS/MS. J Pharm Biomed Anal 2017, 132, 109-116.

14. Hong, Y. H.; Huang, Y. L.; Liu, Y. C.; Tsai, P. J., Djulis (Chenopodium formosanum Koidz.) Water Extract and Its Bioactive Components Ameliorate Dermal Damage in UVB-Irradiated Skin Models. Biomed Res Int 2016, 2016, 7368797.

15. Chyau, C. C.; Chu, C. C.; Chen, S. Y.; Duh, P. D., The Inhibitory Effects of Djulis (Chenopodium formosanum) and Its Bioactive Compounds on Adipogenesis in 3T3-L1 Adipocytes. Molecules 2018, 23 (7).

16. Huang, C. Y.; Chu, Y. L.; Sridhar, K.; Tsai, P. J., Analysis and determination of phytosterols and triterpenes in different inbred lines of Djulis (Chenopodium formosanum Koidz.) hull: A potential source of novel bioactive ingredients. Food Chem 2019, 297, 124948.

17. Sun, L.-C.; Sridha, K.; Tsai, P.-J.; Chou, C.-S., Effect of traditional thermal and high-pressure processing (HPP) methods on the color stability and antioxidant capacities of Djulis (Chenopodium formosanum Koidz.). LWT 
2019, 109, 342-349.

18. Chu, C.-C. C., Shih-Ying, Chyau, Charng-Cherng, Fu, Zi-Han Liu, Chin-Chih, Duh, Pin-Der, Protective effect of Djulis (Chenopodium formosanum) and its bioactive compounds against carbon tetrachloride-induced liver injury, in vivo. Journal of Functional Foods 2016, 26, 585-597.

19. Chang, C.; Yang, M.; H. Wen; Chern, J., Estimation of total flavonoid content in propolis by two complementary colorimetric methods. J. Food Drug Anal. 2002, 10, 178-182.

20. Yarrow, J. C.; Perlman, Z. E.; Westwood, N. J.; Mitchison, T. J., A high-throughput cell migration assay using scratch wound healing, a comparison of image-based readout methods. BMC Biotechnol 2004, 4, 21.

21. Peter-Katalinic, J., Methods in enzymology: O-glycosylation of proteins. Methods Enzymol 2005, 405, $139-71$.

22. Chan, Y. Y., Kim, K. H. Cheah, S H,. Optimization and validation of a cell-based tyrosinase assay for screening of tyrosinase inhibitors. Journal of Health and Translational Medicine 2011, 14 (2), 1-4.

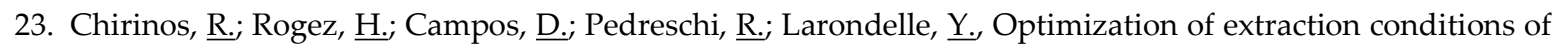
antioxidant phenolic compounds from mashua (Tropaeolum tuberosum Ruíz \& Pavón) tubers. Separation and Purification Technology 2007, 55 (2), 217-225.

24. Chuang, K. J.; Chen, Z. J.; Cheng, C. L.; Hong, G. B., Investigation of the Antioxidant Capacity, Insecticidal Ability and Oxidation Stability of Chenopodium formosanum Seed Extract. Int J Mol Sci 2018, 19 (9).

25. Tsai, P. J.; Chen, Y. S.; Sheu, C. H.; Chen, C. Y., Effect of nanogrinding on the pigment and bioactivity of Djulis ( Chenopodium formosanum Koidz.). J Agric Food Chem 2011, 59 (5), 1814-20.

26. Tsai, P. J.; Sheu, C. H.; Wu, P. H.; Sun, Y. F., Thermal and pH stability of betacyanin pigment of Djulis (Chenopodium formosanum) in Taiwan and their relation to antioxidant activity. J Agric Food Chem 2010, 58 (2), 1020-5.

27. TGM1 Available online: http://www.ncbi.nlm.nih.gov/gene/7051;

28. KRT1 Available online: http://www.ncbi.nlm.nih.gov/gene/3848;

29. KRT10 Available online: http://www.ncbi.nlm.nih.gov/gene/3858;

30. SOD2 Available online: http://www.ncbi.nlm.nih.gov/gene/6648;

31. COL1A2 Available online: http://www.ncbi.nlm.nih.gov/gene/1278;

32. MMP9 Available online: http://www.ncbi.nlm.nih.gov/gene/4318. 


\section{Legends}

\begin{tabular}{|c|c|}
\hline Table.1 & Real-time quantitative PCR primers used in this study. \\
\hline Table.2 & Antioxidative compounds of red djulis extract. \\
\hline Figure.1 & Appearance of red djulis (Chenopodium formosanum) \\
\hline Figure.2 & The HPLC profile of Chenopodium formosanum extracts. \\
\hline Figure.3 & $\begin{array}{l}\text { Chemical characterization all isolates from Chenopodium } \\
\text { formosanum extracts. }\end{array}$ \\
\hline Figure.4 & $\begin{array}{l}\text { Cytotoxicity test of red djulis extracts at different } \\
\text { concentrations. }\end{array}$ \\
\hline Figure.5 & $\begin{array}{l}\text { Wound healing effect of red djulis extracts at different } \\
\text { concentrations. }\end{array}$ \\
\hline Figure.6 & $\begin{array}{l}\text { Relative TGM1, KRT1, KRT10 and SOD2 gene expression in } \\
\text { fibroblasts with or without red djulis extract treatment }\left({ }^{*} p<0.5 \text {; }\right. \\
\left.{ }_{* * *}<<0.001\right) \text {. }\end{array}$ \\
\hline Figure.7 & $\begin{array}{l}\text { Relative COL1A2 and MMP9 gene expression in fibroblasts } \\
\text { with or without red djulis extract treatment }\left({ }^{* *} p<0.01\right) \text {. }\end{array}$ \\
\hline Figure.8 & $\begin{array}{l}\text { Effects of red djulis extracts in fibroblasts with or without red } \\
\text { djulis extract treatment: (a) Collagen immunofluorescence } \\
\text { staining (b) collagen secretion of red djulis extracts treatment } \\
\text { and (c) collagen secretion of different red djulis extract fractions } \\
\text { treatment. }\end{array}$ \\
\hline
\end{tabular}




\begin{tabular}{|l|l|}
\hline Figure.9 & $\begin{array}{l}\text { The effect of red djulis extracts on formation of Advanced } \\
\text { Glycation End-products (AGEs). }\end{array}$ \\
\hline Figure.10 & Effect of red djulis extracts on tyrosinase activity. \\
\hline
\end{tabular}


Table 1.

\begin{tabular}{|c|c|c|c|c|}
\hline $\begin{array}{l}\text { Gene } \\
\text { Name }\end{array}$ & Primer Name & Primer Sequence & Gene Function & Reference \\
\hline \multirow[t]{2}{*}{ TGM1 } & TGM1-F & $\begin{array}{c}\text { 5'- GATCGCATCACCCTTGAGTTAC - } \\
3^{\prime}\end{array}$ & \multirow[t]{2}{*}{$\begin{array}{l}\text { epidermal barrier } \\
\text { structural genes }\end{array}$} & \multirow[t]{2}{*}{27} \\
\hline & TGM1-R & 5'- GCAGGTTCAGATTCTGCCC -3' & & \\
\hline \multirow[t]{2}{*}{ KRT10 } & KRT10-F & $\begin{array}{c}\text { 5'- TCCTACTTGGACAAAGTTCGGG - } \\
3^{\prime}\end{array}$ & \multirow[t]{2}{*}{$\begin{array}{l}\text { epidermal barrier } \\
\text { structural genes }\end{array}$} & \multirow[t]{2}{*}{28} \\
\hline & KRT10-R & 5'- CCCCTGATGTGAGTTGCCA -3' & & \\
\hline \multirow[t]{2}{*}{ KRT14 } & KRT14-F & 5'- TTCTGAACGAGATGCGTGAC -3' & \multirow[t]{2}{*}{ epidermal barrier } & \multirow[t]{2}{*}{29} \\
\hline & KRT14-R & 5'- GCAGCTCAATCTCCAGGTTC -3' & & \\
\hline \multirow[t]{2}{*}{ SOD1 } & SOD1-F & $\begin{array}{c}\text { 5'- GGTGGGCCAAAGGATGAAGAG - } \\
3^{\prime}\end{array}$ & \multirow[t]{2}{*}{ anti-oxidative gene } & \multirow[t]{2}{*}{30} \\
\hline & SOD1-R & 5'- CCACAAGCCAAACGACTTCC -3' & & \\
\hline \multirow[t]{2}{*}{ COL1A2 } & COL1A1-F & ATCAACCGGAGGAATTTCCGT & \multirow[b]{2}{*}{$\begin{array}{l}\text { making part type I } \\
\text { collagen }\end{array}$} & \multirow[t]{2}{*}{31} \\
\hline & COL1A1-R & CACCAGGACGACCAGGTTTTC & & \\
\hline \multirow[t]{2}{*}{ MMP9 } & MMP9-F & GGGACGCAGACATCGTCATC & \multirow[b]{2}{*}{$\begin{array}{l}\text { degradation and } \\
\text { remodeling of extracellular } \\
\text { matrix (ECM) }\end{array}$} & \multirow[t]{2}{*}{32} \\
\hline & MMP9-R & TCGTCATCGTCGAAATGGGC & & \\
\hline
\end{tabular}


Table. 2

\begin{tabular}{|c|c|c|c|}
\hline & Extraction & Total flavones content & phenolic \\
\hline & Temperature $\left({ }^{\circ} \mathrm{C}\right)$ & $(\mathrm{mg} / \mathrm{mL})$ & content \\
\hline & & & $(\mathrm{mg} / \mathrm{mL})$ \\
\hline Unhulled & 25 & $418 \pm 14$ & $326 \pm 26$ \\
\hline \multirow[t]{2}{*}{ red djulis } & 50 & $418 \pm 4$ & $332 \pm 18$ \\
\hline & 70 & $421 \pm 8$ & $318 \pm 20$ \\
\hline Hulled red & 25 & $105 \pm 7$ & $110 \pm 2$ \\
\hline \multirow[t]{2}{*}{ djulis } & 50 & $116 \pm 9$ & $90 \pm 18$ \\
\hline & 70 & $87 \pm 9$ & $73 \pm 11$ \\
\hline
\end{tabular}




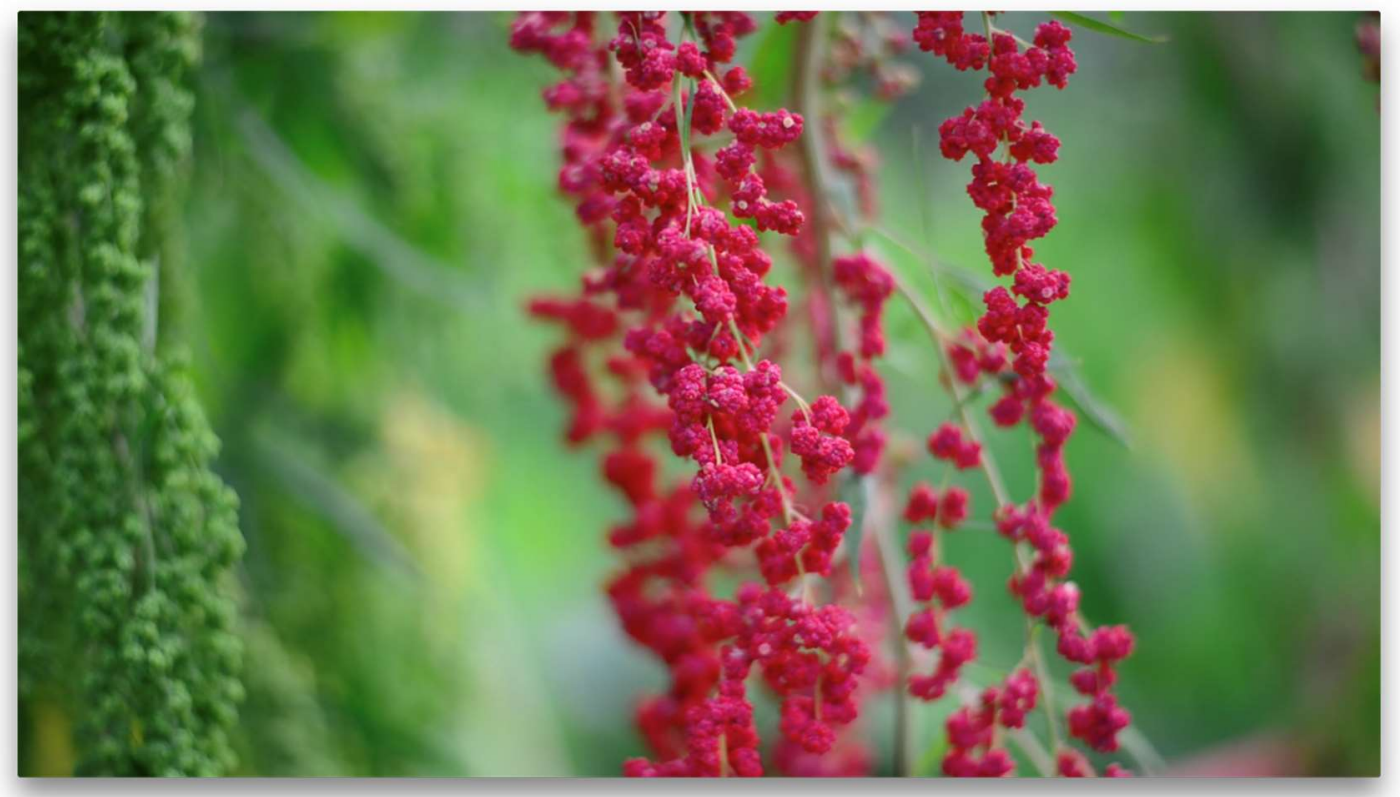

Figure. 1 


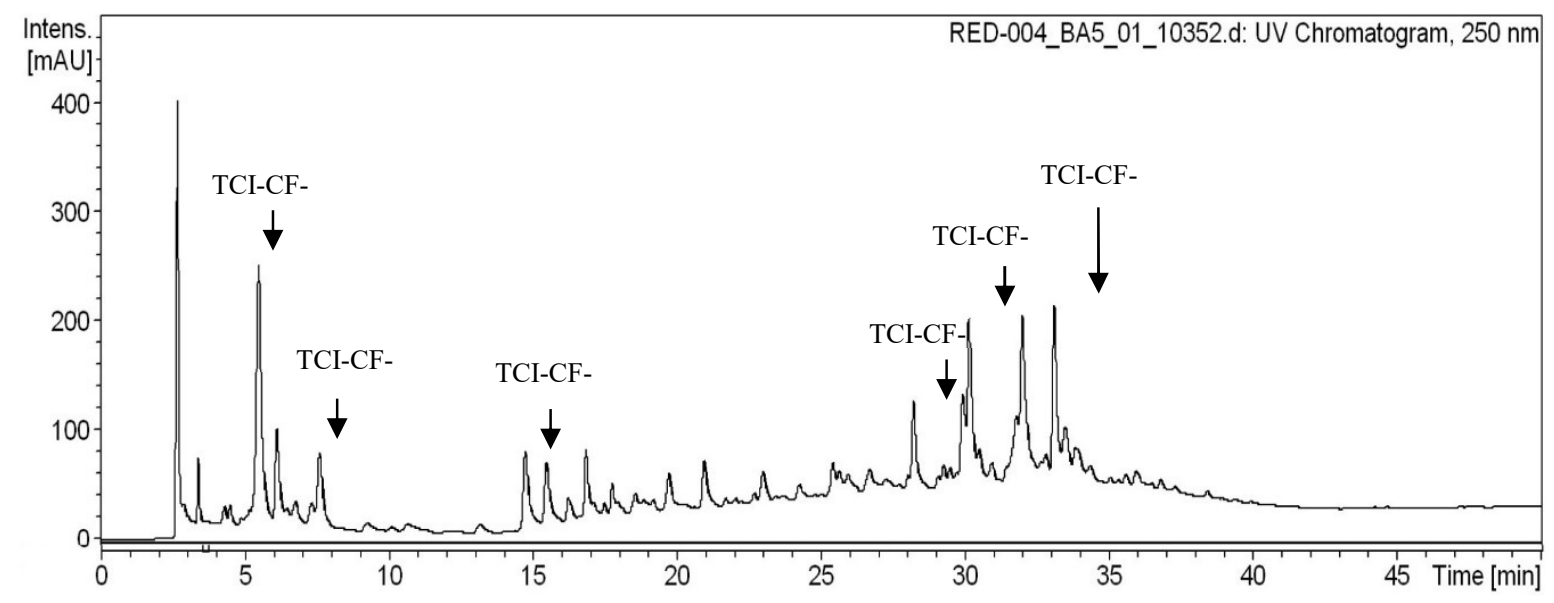

Figure. 2 
<smiles>O=C(O)/C=C/c1ccc(O)c(O)c1</smiles><smiles>O=C(O)Cc1ccc(O)c(O)c1</smiles><smiles>C[C@@H]1OC(OC[C@H]2OC(Oc3c(-c4ccc(O)c(O)c4)oc4cc(OC5O[C@H](C)[C@@H](O)[C@H](O)[C@H]5O)cc(O)c4c3=O)[C@H](O)[C@@H](O)[C@@H]2O)[C@H](O)[C@@H](O)[C@@H]1O</smiles>

TCl-CF-03<smiles>Nc1nc2c(ncn2C2O[C@H](CO)[C@@H](O)[C@H]2O)c(=O)[nH]1</smiles>

TCl-CF-04<smiles>CC(C)(O)CC[C@H](O)[C@](C)(O)C1CC[C@]2(O)C3=CC(=O)C4C[C@@H](O)[C@@H](O)C[C@]4(C)C3CC[C@]12C</smiles>

TCI-CF-05<smiles>Nc1ncnc2[nH]cnc12</smiles>

TCI-CF-06

Figure. 3 


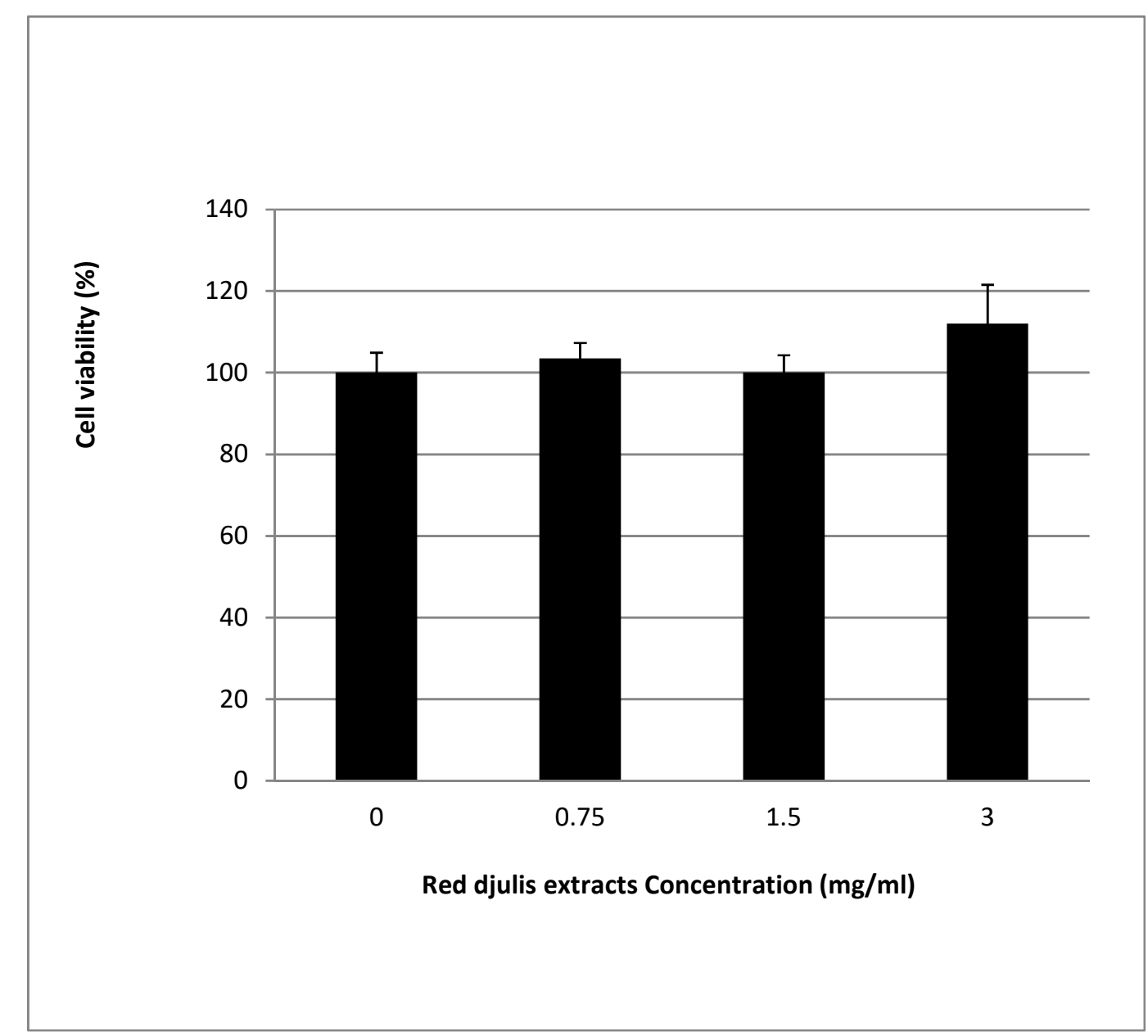

Figure. 4 


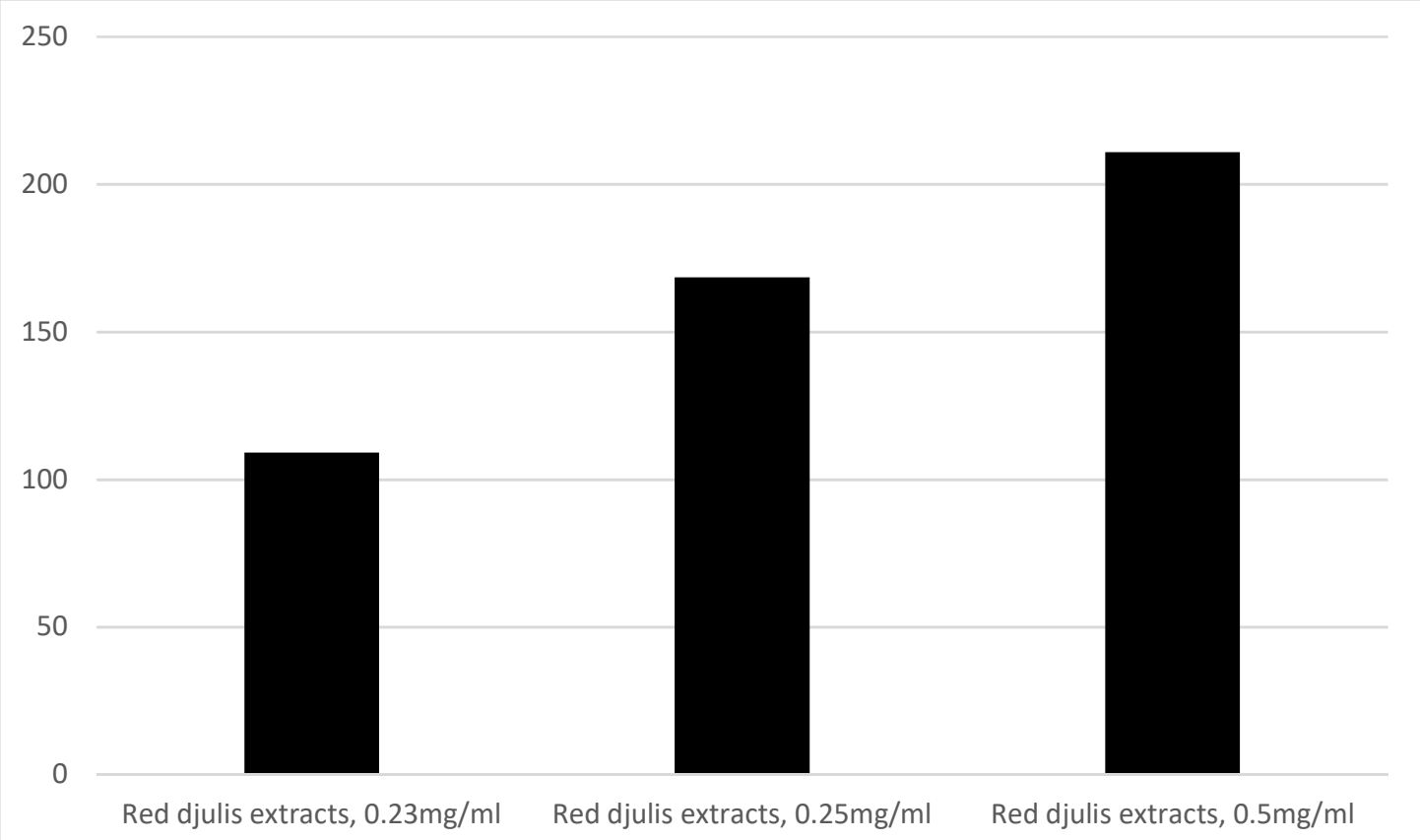

Figure. 5 


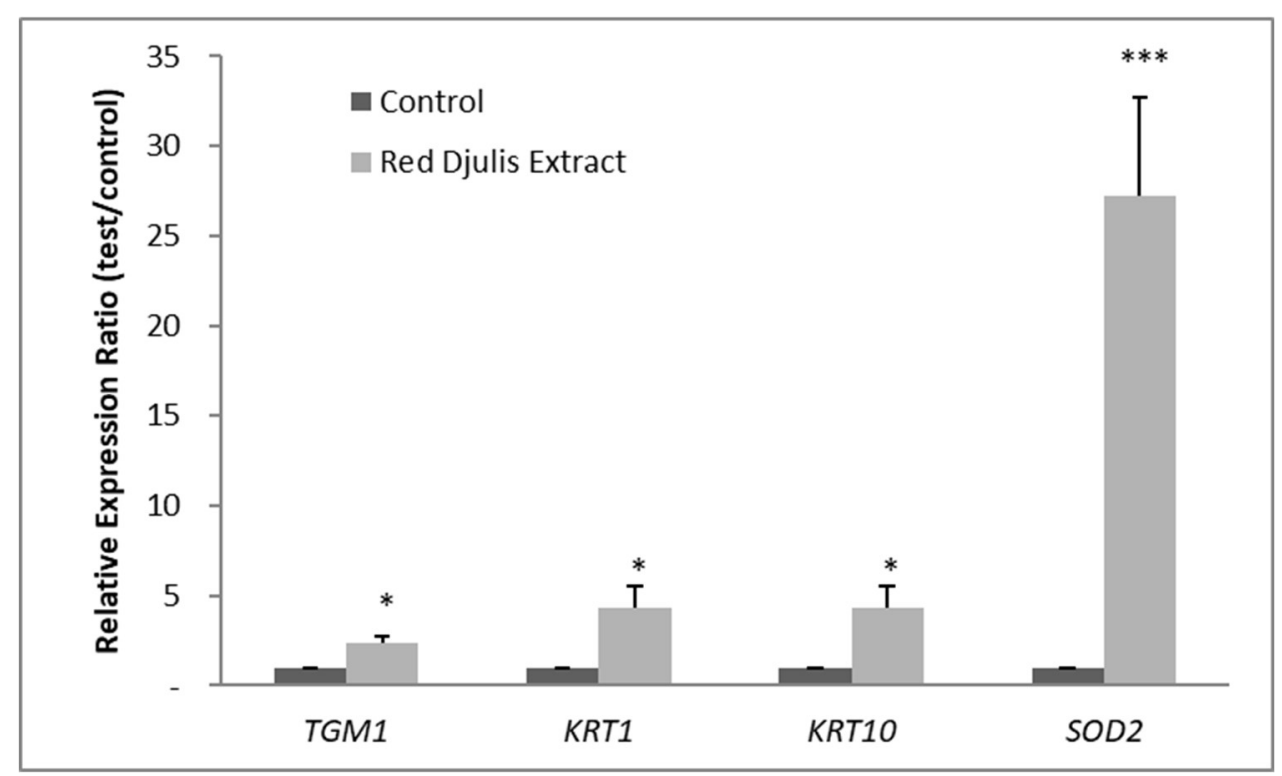

Figure 6. 


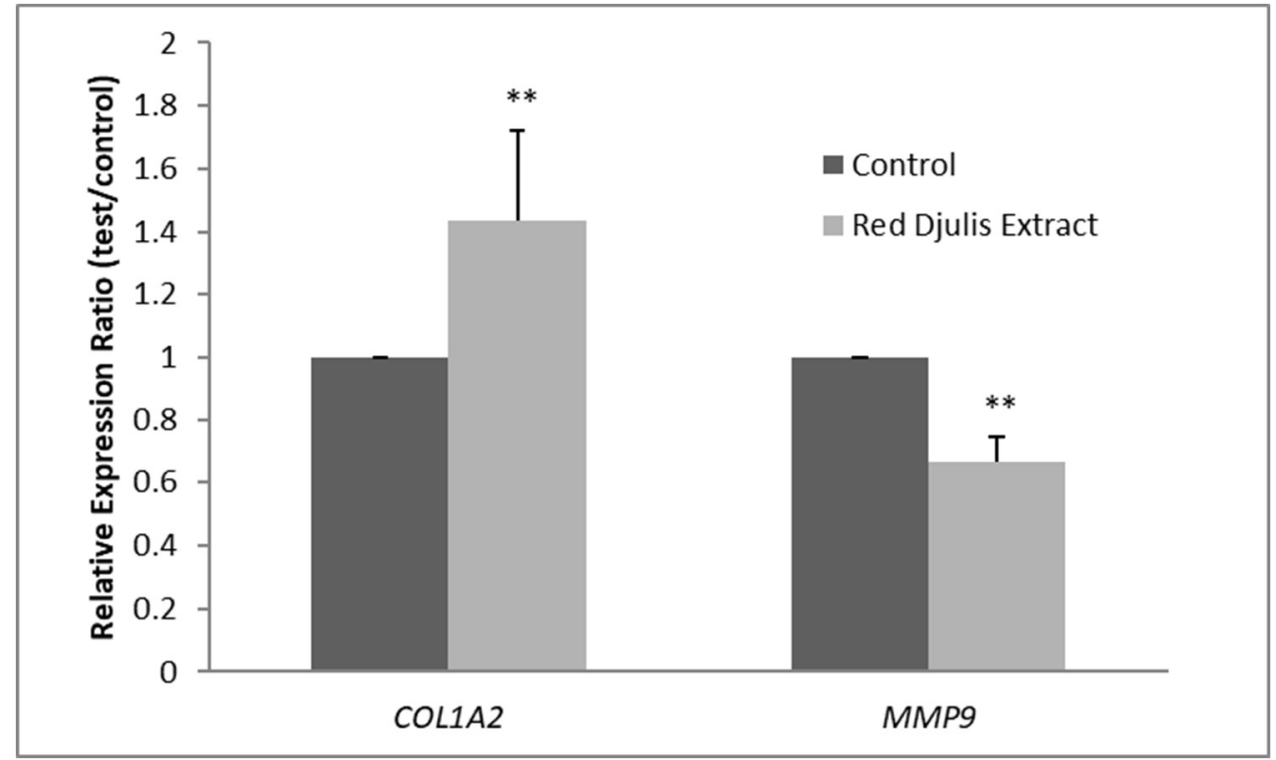

Figure. 7 
(a)
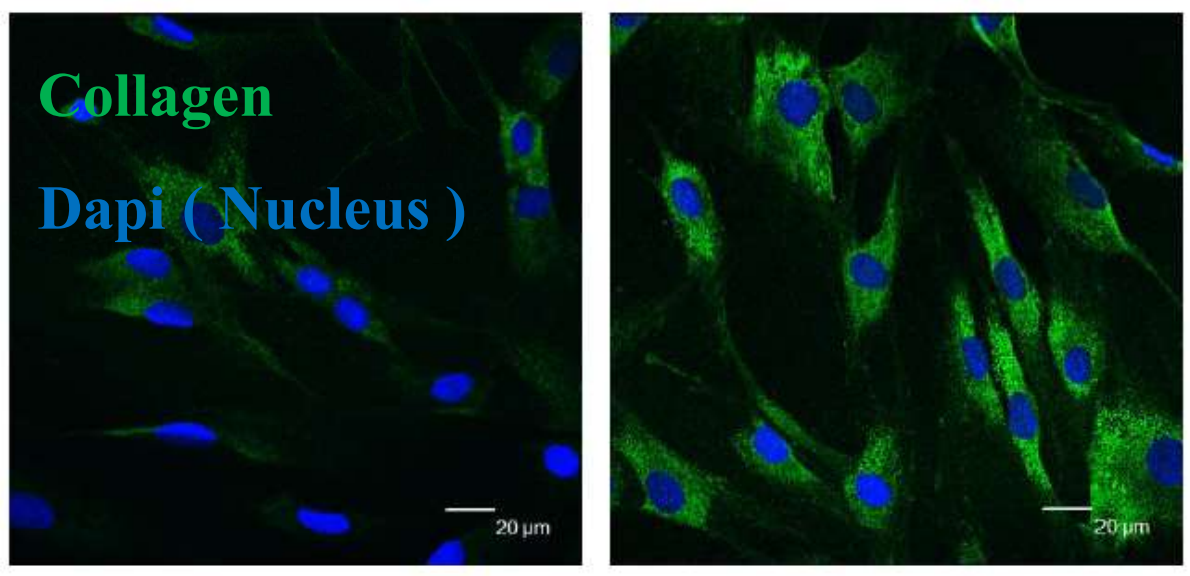

Control

Red Djulis Extract

(b)

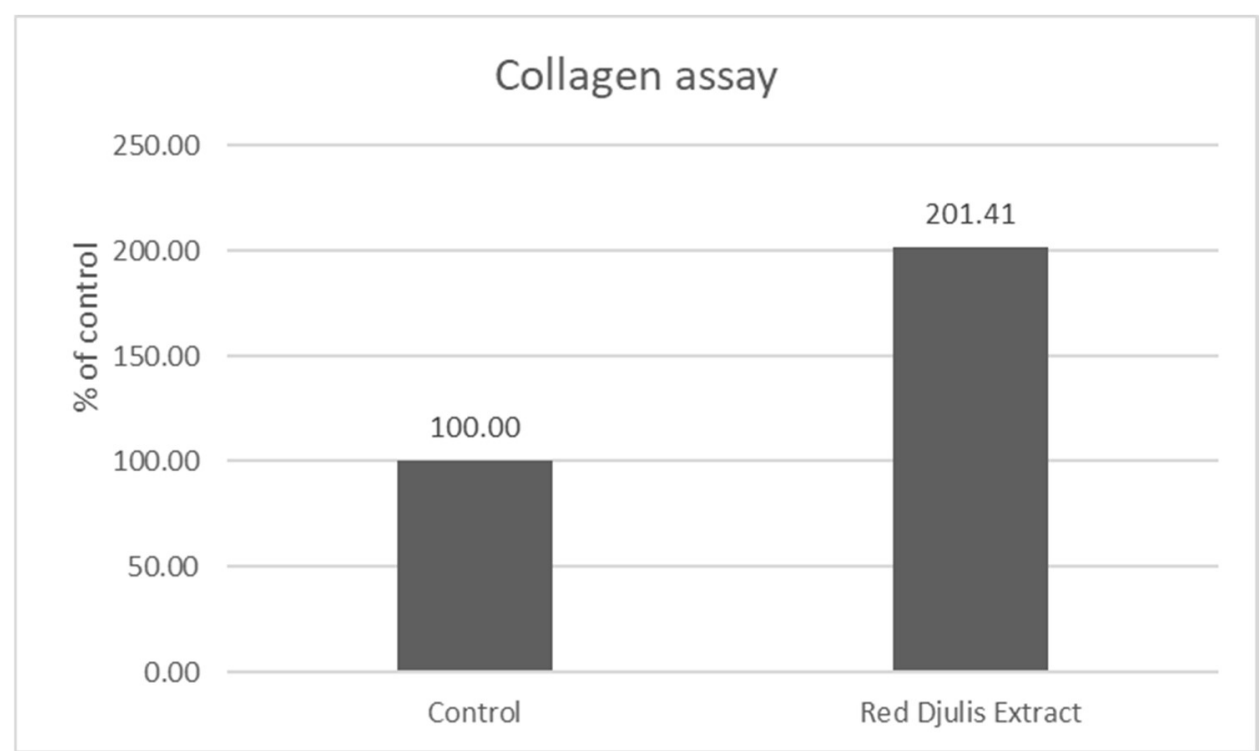


(c)

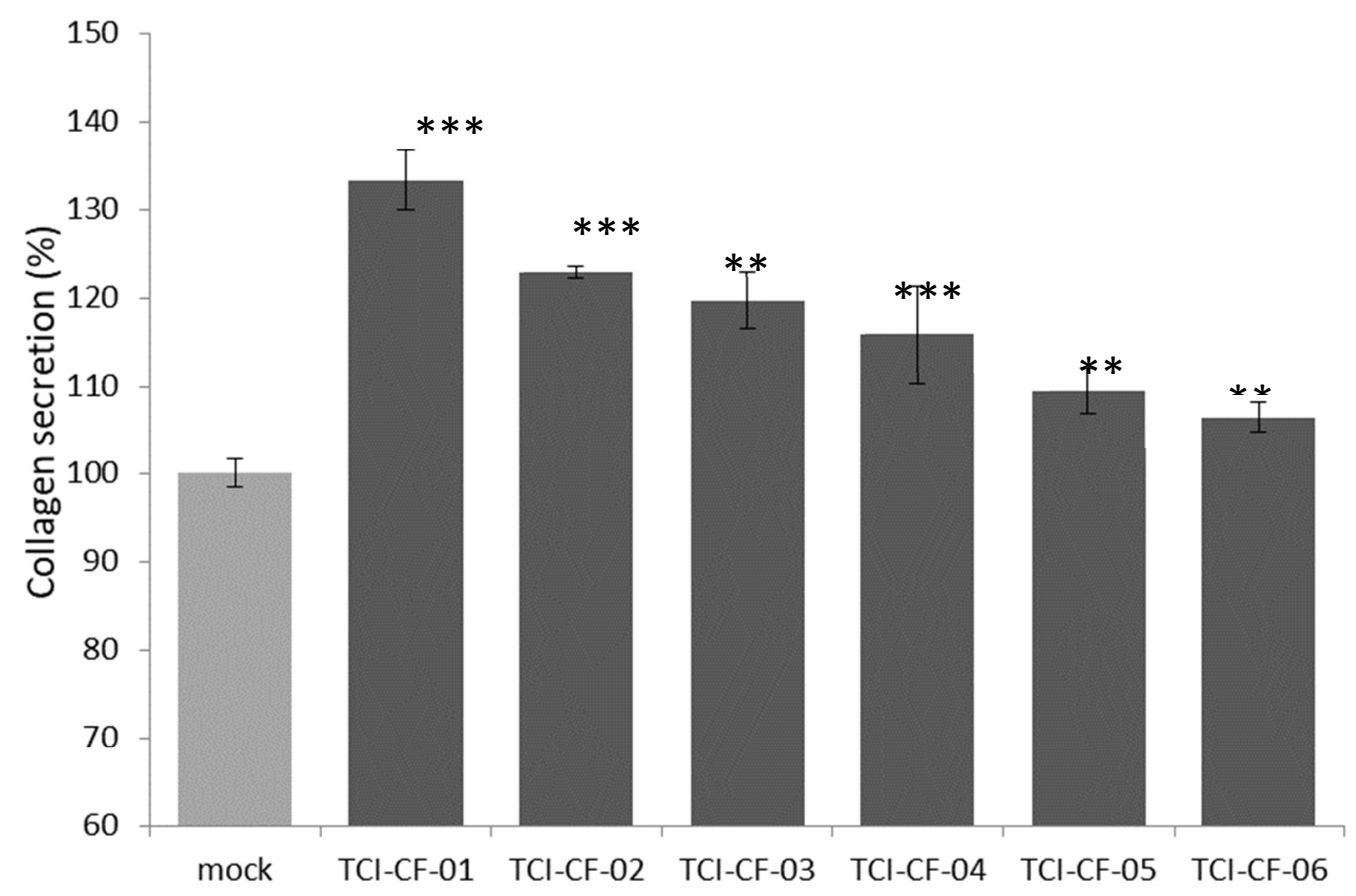

Figure. 8 


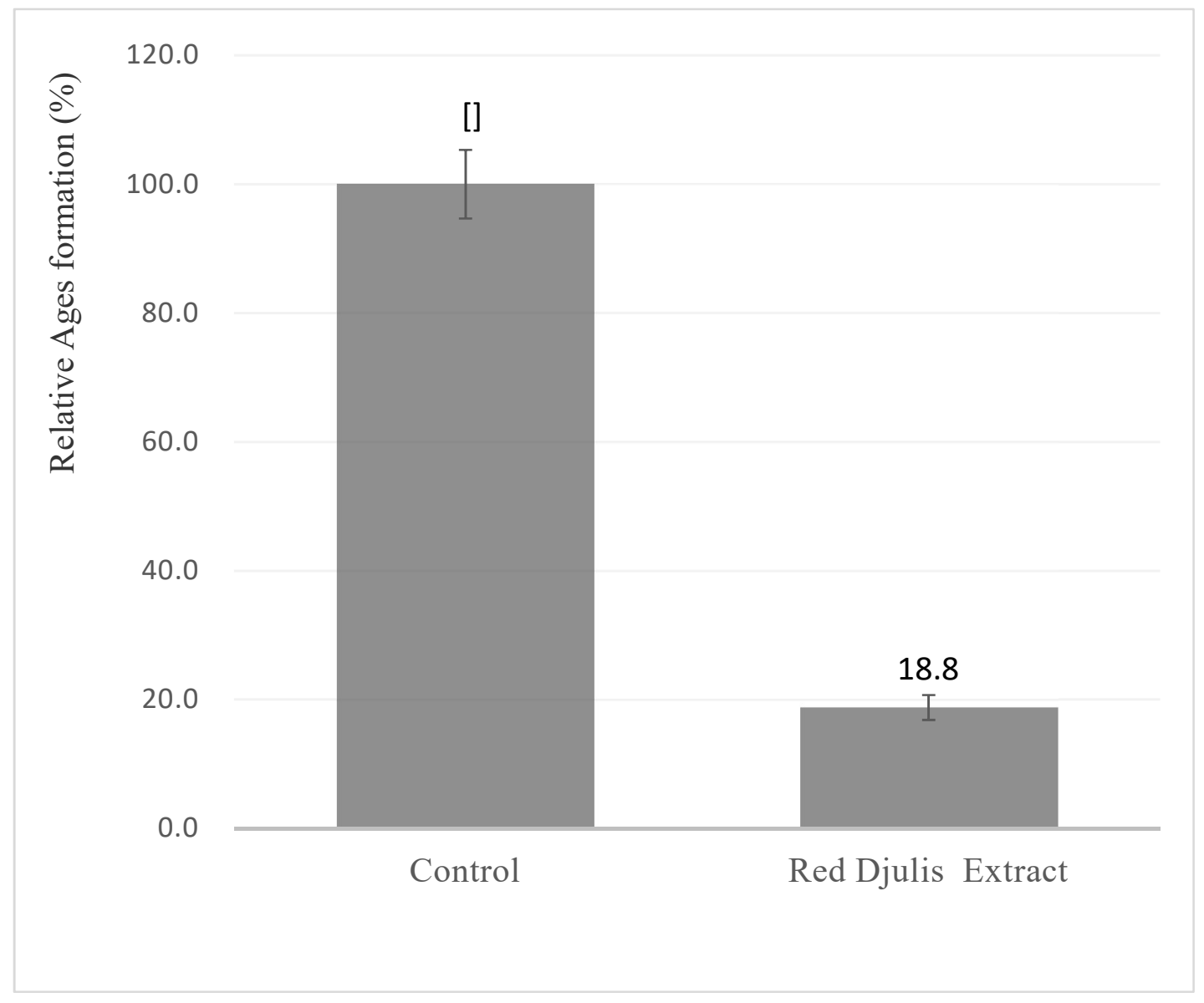

Figure. 9 


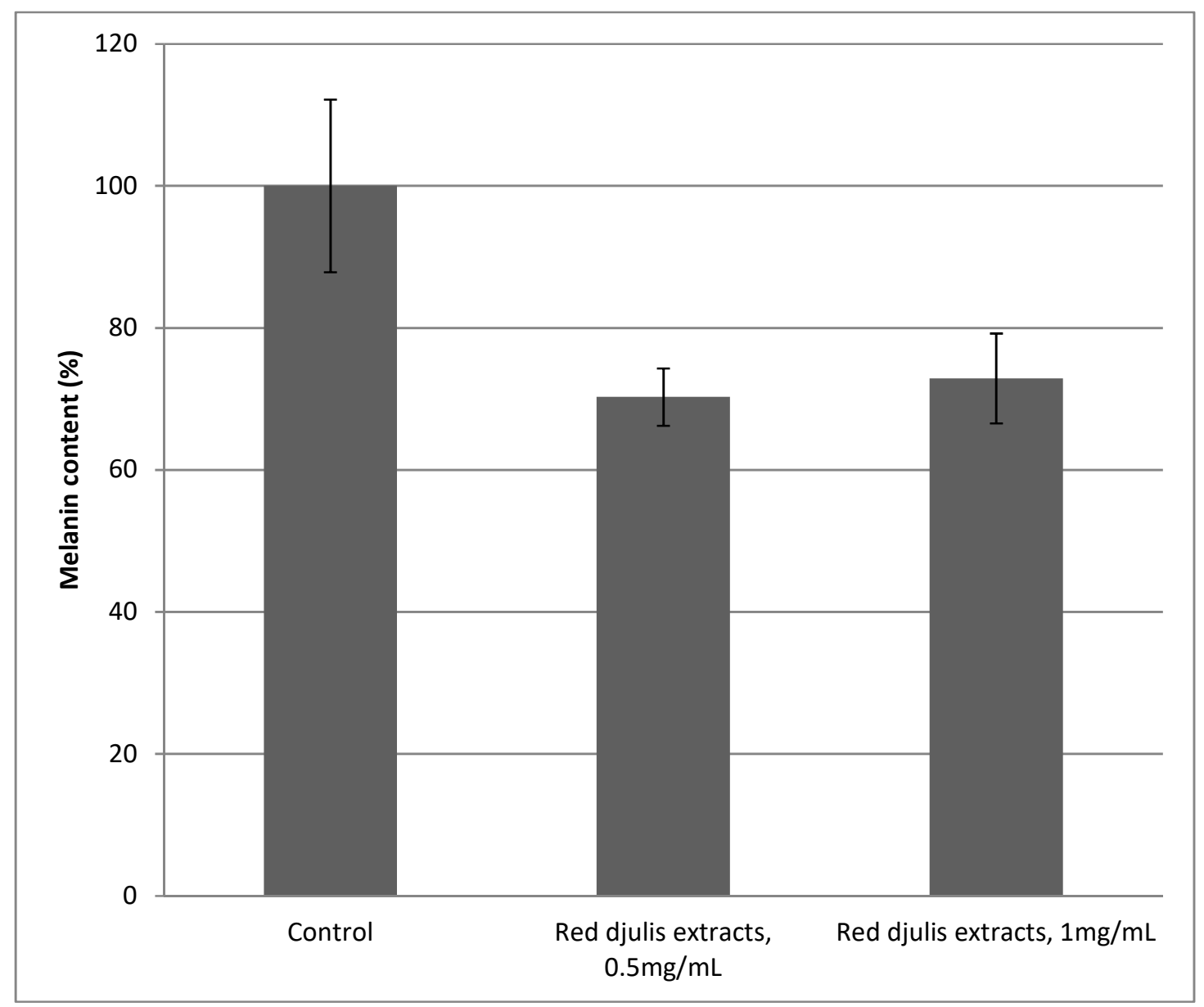

Figure 10 